\title{
Role of Vascular Endothelial Growth Factor in Clinically Localized Prostate Cancer Treated with Radiation Therapy
}

\author{
Eda Yirmibeşoğlu Erkal ${ }^{1,2}$, Hüseyin Bora ${ }^{1}$, Merih Tepeoğlu ${ }^{3,4}$, Müge Akmansu ${ }^{1}$ \\ ${ }^{1}$ Department of Radiation Oncology, Gazi University Faculty of Medicine, Ankara, Turkey \\ ${ }^{2}$ Department of Radiation Oncology, Kocaeli University Faculty of Medicine, Kocaeli, Turkey \\ ${ }^{3}$ Department of Pathology, Gazi University Faculty of Medicine, Ankara, Turkey \\ ${ }^{4}$ Department of Pathology, Başkent University Faculty of Medicine, Ankara, Turkey
}

Background: Anti-vascular endothelial growth factor (Anti-VEGF) agents are a promising approach to increase the efficacy of treatment for treatment-resistant prostate cancer.

Aims: To correlate vascular endothelial growth factor (VEGF) expression and outcome following radiation therapy in the treatment of clinically localized prostate cancer.

Study Design: Retrospective observational study.

Methods: Forty-one patients and clinically localized disease that were treated with radiation therapy were analyzed. For VEGF expression, immunoreactivity scores (IRS) were calculated using percent scores and intensity scores. Twenty-four patients were classified as having low ( 0 to 4 IRS) and 17 patients were classified as having high (5 to 8 IRS) VEGF expression.

Results: The median age was 71 years, median follow-up was 5.4 years and median radiation therapy dose was 70 Gy. VEGF expression was calculated as low in 24 patients and high in 17 patients.
Higher VEGF expression was observed in 6/26 patients with a low Gleason score versus $11 / 15$ patients with a high Gleason score $(\mathrm{p}=0.02)$. Biochemical failure $(\mathrm{BF})$ was observed in $2 / 24$ patients with low VEGF expression versus $7 / 17$ patients with high VEGF expression $(\mathrm{p}=0.01)$. In univariate analysis, having a higher Gleason score $(\mathrm{p}<0.01)$, being in the high risk group $(\mathrm{p}=0.03)$ and having higher VEGF expression $(\mathrm{p}=0.01)$ predicted $\mathrm{BF}$ after definitive radiation therapy. The biochemical failure-free survival rate at 5 years tended to be different $(91 \%$ vs. $53 \%)$ when patients were grouped according to VEGF expression ( $\mathrm{p}=0.06)$.

Conclusion: In attempt to define patients with clinically localized disease that are not sensitive to standard treatment modalities, cellular and/or molecular biological markers may be required.

(Balkan Med J 2014;31:43-49).

Key Words: Prostate cancer, radiation therapy, vascular endothelial growth factor (VEGF)
Although developments in radiation therapy techniques have improved outcomes for patients with clinically localized prostate cancer, relapse remains an issue despite the addition of hormonal therapy (1). Although treatment failure following radiation therapy depends on various parameters, the hypoxic microenvironment of the tumor can also provide an explanation. In clinically localized prostate cancer, tumor hypoxia has been linked to higher biochemical failure (BF) rates and poorer prognosis (2). Hypoxia and angiogenesis are important factors in tumorigenesis and the response to cancer treatment. Vascular endothelial growth factor (VEGF) is a key molecule in angiogenesis that has a major role in cancer growth. High VEGF expression is the result of adaptation to low oxygenation (hypoxia) in the microenvironment of tumor $(3,4)$.

The principal antitumor mechanism of antiangiogenic agents is through the inhibition of endothelial cell function, an event that leads to a reduction in tumor blood flow, tumor hypoxia, and cell death. The use of novel targeted therapies, such as
anti-VEGF agents, in addition to standard therapies is a promising approach to increase the efficacy of treatment for resistant disease. Studies have shown that anti-VEGF agents can enhance radiation-induced inhibition of tumor growth $(5,6)$. Increased VEGF expression has predicted a shorter time to BF following definitive radiation therapy, regardless of clinical stage, Gleason score, prostate specific antigen (PSA) level, and radiation dose (7). The aim of the present study was to correlate VEGF expression with outcome in patients with clinically localized prostate cancer treated with radiation therapy.

\section{MATERIAL AND METHODS}

\section{Patient population}

Between 1997 and 2006, 264 patients with prostate cancer were treated with radiation therapy at the Department of Radiation On- 
cology, Gazi University Faculty of Medicine. Those patients who did not have clinically localized disease, who had undergone radical prostatectomy prior to radiation therapy, who had received a total dose $<66$ Gy, who had been treated with palliative intent or who had diagnostic biopsies performed at other institutions were excluded. As a consequence, 41 patients who had received radiation therapy (with or without hormonal therapy) with curative intent for clinically localized disease were included in this study. Oral informed consent was obtained from patients who participated in this study. All patients had adenocarcinomas. Their medical records were reviewed to assess disease and treatment characteristics and the presence or absence of BF. The end of the follow-up period was March 2009.

Clinical $\mathrm{T}$ stage was $\mathrm{T} 1 \mathrm{c}$ to $\mathrm{T} 2 \mathrm{a}$ in 22 patients $(54 \%)$ and $\geq \mathrm{T} 2 \mathrm{~b}$ in 19 patients (46\%). At the time of diagnosis, the mean PSA level was $17.9 \mathrm{ng} / \mathrm{mL}(2-66 \mathrm{ng} / \mathrm{mL})$ and the PSA levels of 21 patients $(51 \%)$ were $\leq 10 \mathrm{ng} / \mathrm{mL}$. Gleason scores reported from transrectal biopsies were $\leq 6$ in 26 patients $(63 \%)$ and $>6$ in 15 patients (37\%) (Table 1 ). According to the risk classification scheme proposed by D'Amico et al. (8), 18 patients (44\%) were classified into the low-risk group, eight patients $(19.5 \%)$ were classified into the intermediate-risk group and 15 patients $(36.5 \%)$ were classified into the high-risk group.

\section{Treatment technique}

All patients were treated with high energy linear accelerators (10 MV and/or 15 MV photon beams) (Saturn 41, General Electric, Buc, France). Patients were generally treated with the four-field box technique. Planning treatment volume was the prostate and the vesicles with margins. Regional nodes were prophylactically included for high risk patients (with PSA $>20 \mathrm{ng} / \mathrm{mL}$ and/or Gleason score $>7$ ). The majority of patients were treated to 70 Gy with daily fractions of 2 Gy. Ten patients $(24 \%)$ were treated with radiation therapy alone while 31 patients $(76 \%)$ received either short-term (17 patients) or long-term (14 patients) hormonal therapy (Table 1). All patients had PSA testing at regular three-monthly intervals during follow-up.

\section{Assessment of VEGF expression}

Tissue sections of $4 \mu \mathrm{m}$ were cut from previously prepared representative formalin-fixed and paraffin-embedded blocks. Sections were deparaffinized in xylene and rehydrated. Immunoperoxidase staining was performed using the streptavidin-biotin peroxidase method. The sections were treated with $0.3 \% \mathrm{H}_{2} \mathrm{O}_{2}$ in order to suppress endogenous peroxidase activity. Sections were pretreated with ethylenediaminetetraacetic acid (EDTA) to retrieve antigen expression and incubated with anti-VEGF monoclonal antibody (1:50 diluted, clone VG1, NeoMarkers). As a chromogen for color development, 3-amino-9-ethylcarbazole substrate (AEC; LabVision, NeoMarkers) was used. The slides were counterstained with hematoxylin, dehydrated and mounted. Sections of angiosarcoma were used as the positive control. For the negative control, phosphate buffered saline replaced the primary antibody. Stained slides were examined to identify VEGF immunoreactivity. VEGF expression was assessed using a semiquantitative scoring method that was blinded to patient outcome. The percentage of positively stained glands (none $=0$; less than $1 \%=1$, $1-10 \%=2 ; 11-33 \%=3 ; 34-67 \%=4$; and more than $67 \%=5)$ and the staining intensity (none $=0$; weak $=1$; moderate $=2$; strong $=3$ ) were evaluated. The percentage scores and the intensity scores were added to give a final immunoreactivity score (IRS) that ranged from 0 to 8 . For the purpose of statistical analysis, IRS was classified as low (0 to 4) or high (5 to 8) (9).

\section{Statistical analysis}

For the purpose of statistical analysis (due to the limited number of patients), the intermediate-risk group and the high-risk group were merged to define low-risk patients (clinical T stage T1c to T2a, initial $\mathrm{PSA} \leq 10 \mathrm{ng} / \mathrm{mL}$ and Gleason score $\leq 6$ ) and high-risk patients (clinical $\mathrm{T}$ stage $\geq \mathrm{T} 2 \mathrm{~b}$ and/or initial PSA $>10 \mathrm{ng} / \mathrm{mL}$ and/or Gleason score $\geq 7$ ). $\mathrm{BF}$ was defined as rising PSA levels in three consecutive measurements following radiation therapy. Overall survival (OS) was calculated from the final day of radiation therapy to death. Patients who were alive were censored at their last follow-up for OS. Biochemical failure-free survival (BFFS) was calculated from the final day of radiation therapy to the time when BF was established. Patients dying without $\mathrm{BF}$ were classified as censored observations at the time of death and all other patients were censored at their last follow-up for the BFFS.

Statistical analysis was performed using SPSS for Windows version 17.0 (SPSS Inc., 2008, Chicago, IL, USA). Differences between patient groups were evaluated using the chi-square test. Survival estimations were performed using the method of Kaplan and Meier, univariate analysis using the log-rank test and log-rank test for linear trend. Statistical significance was considered when the p-value was less than or equal to 0.05 .

\section{RESULTS}

The median age was 71 years (range, $58-82$ years). The median radiation therapy dose was $70 \mathrm{~Gy}$, ranging from 66 to 74 Gy. Follow-up ranged from 3 to 12.2 years (median, 5.4 years).

\section{VEGF expression}

VEGF expression was evaluated as low in 24 patients (59\%) and high in 17 patients (41\%) (Table 1). Higher VEGF expression was observed in 16 out of 22 patients with a low clinical $\mathrm{T}$ stage as compared to in 8 out of 19 patients with a high clinical T stage, the difference being statistically significant $(\mathrm{p}=0.05$, $\left.\chi^{2}=3.94\right)$. VEGF was overexpressed in 7 out of 21 patients with a low initial PSA level as compared to 10 out of 20 patients with a high initial PSA level; this difference was not statistically significant $\left(p>0.05, \chi^{2}=1.17\right)$. On the contrary, higher VEGF expression was observed in 6 out of 26 patients with a low Gleason score as compared to in 11 out of 15 patients with a high Gleason score; this difference was statistically significant 
$\left(\mathrm{p}=0.02, \chi^{2}=9.89\right)$. However, when defined risk groups based on the initial PSA level and Gleason score were analyzed, VEGF was overexpressed in 4 out of 18 patients in the low risk group as compared to in 13 out of 23 patients in the high risk group; this difference was statistically significant $\left(\mathrm{p}=0.03, \chi^{2}=4.89\right)$.

\section{Biochemical failure}

For the entire group, BF was observed in 9 patients (22\%). BF was observed in none of the 22 patients with a low clinical $T$ stage as compared to in 9 out of 19 patients with a high clinical

TABLE 1. Patient characteristics

\begin{tabular}{ll}
\hline & $\mathrm{N}(\%)$ \\
\hline Age & \\
$\quad<71$ years & $20(49)$ \\
$\quad \geq 71$ years & $21(51)$ \\
Clinical T stage & \\
$\quad$ T1c and T2a & $22(54)$ \\
$\quad \geq$ T2b & $19(46)$ \\
Initial PSA level & \\
Low ( $\leq 10 \mathrm{ng} / \mathrm{mL})$ & $21(51)$ \\
$\quad$ High $(>10 \mathrm{ng} / \mathrm{mL})$ & $20(49)$ \\
Gleason score & \\
$\quad$ Low $(<7)$ & $26(63)$ \\
High $(\geq 7)$ & $15(37)$ \\
Risk group & $18(44)$ \\
$\quad$ Low-risk patients & $23(56)$ \\
High-risk patients & \\
VEGF expression & $24(59)$ \\
Low $(0-4)$ & $17(41)$ \\
$\quad$ High $(5-8)$ & \\
\hline N: number of patients; PSA: prostate specific antigen; VEGF: vascular endothelial \\
growth factor
\end{tabular}

T stage; this difference was statistically significant $(\mathrm{p}<0.001$, $\chi^{2}=13.35$ ). BF was observed in 3 out of 21 patients with a low initial PSA level as compared to 6 out of 20 patients with a high initial PSA level; this difference was not statistically significant ( $\left.p>0.05, \chi^{2}=1.48\right)$. On the contrary, BF was observed in 1 out of 26 patients with a low Gleason score as compared to in 8 out of 15 patients with a high Gleason score; this difference was statistically significant $\left(\mathrm{p}<0.001, \chi^{2}=13.59\right)$. However, when defined risk groups based on the initial PSA level and Gleason score were analyzed, BF was reported in none of the 18 patients in the low risk group as compared to in 9 out of 23 patients in the high risk group; this difference was statistically significant $\left(\mathrm{p}=0.03, \chi^{2}=9.02\right)$. BF was observed in 2 out of 24 patients with low VEGF expression as compared to in 7 out of 17 patients with high VEGF expression; this difference was statistically significant $\left(\mathrm{p}=0.01, \chi^{2}=6.27\right)$.

In the univariate analysis, having a higher clinical $\mathrm{T}$ stage $(p<0.001)$, having a higher Gleason score $(p<0.01)$, being in the high risk group $(\mathrm{p}=0.03)$ and having higher VEGF expression $(\mathrm{p}=0.01)$ were predictors of $\mathrm{BF}$ after definitive radiation therapy (Table 2).

\section{Biochemical failure free survival}

The biochemical failure free survival (BFFS) rate at 5 years was $76 \%$ for the entire group of patients. The BFFS rate at 5 years was $100 \%$ vs. $46 \%$ when patients were grouped according to clinical $\mathrm{T}$ stage ( $\mathrm{p}<0.001), 86 \%$ vs. $63 \%$ when patients were grouped according to the initial PSA level ( $\mathrm{p}=0.17)$, $96 \%$ vs. $42 \%$ when patients were grouped according to the Gleason score $(\mathrm{p}<0.01)$ and $100 \%$ vs. $54 \%$ when patients were grouped according to risk groups $(\mathrm{p}=0.001)$. The BFFS rate at 5 years tended to be different $(91 \%$ vs. $53 \%)$ when pa-

TABLE 2. Biochemical failure (BF) and biochemical failure-free survival (BFFS) at 5 years by patient characteristics

\begin{tabular}{|c|c|c|c|c|c|}
\hline & \multicolumn{3}{|c|}{$\mathrm{BF}$} & \multicolumn{2}{|c|}{ BFFS at 5 years } \\
\hline & $\mathrm{N}(\%)$ & p-value & $\chi^{2}$ & $\%(\mathrm{n})$ & p-value \\
\hline \multicolumn{6}{|l|}{ Clinical T stage } \\
\hline $\mathrm{T} 1 \mathrm{c}$ and $\mathrm{T} 2 \mathrm{a}$ & $0(0)$ & $<0.001$ & 13.35 & $100 \pm 0(\mathrm{n}=22)$ & $<0.001$ \\
\hline$\geq \mathrm{T} 2 \mathrm{~b}$ & $9(47)$ & & & $46 \pm 13(n=4)$ & \\
\hline \multicolumn{6}{|l|}{ Initial PSA level } \\
\hline Low $(\leq 10 \mathrm{ng} / \mathrm{mL})$ & $3(14)$ & $>0.05$ & 1.48 & $86 \pm 8(n=8)$ & 0.17 \\
\hline $\operatorname{High}(>10 \mathrm{ng} / \mathrm{mL})$ & $6(30)$ & & & $63 \pm 12(\mathrm{n}=6)$ & \\
\hline \multicolumn{6}{|l|}{ Gleason score } \\
\hline Low $(<7)$ & $1(4)$ & $<0.001$ & 13.59 & $96 \pm 4(n=11)$ & $<0.01$ \\
\hline $\operatorname{High}(\geq 7)$ & $8(53)$ & & & $42 \pm 14(\mathrm{n}=3)$ & \\
\hline \multicolumn{6}{|l|}{ Risk Group } \\
\hline Low-risk patients & $0(0)$ & 0.03 & 9.02 & $100 \pm 0(n=18)$ & 0.001 \\
\hline High-risk patients & $9(39)$ & & & $54 \pm 11(\mathrm{n}=6)$ & \\
\hline \multicolumn{6}{|l|}{ VEGF expression } \\
\hline Low $(0-4)$ & $2(8)$ & 0.01 & 6.27 & $91 \pm 6(n=9)$ & 0.06 \\
\hline High (5-8) & $7(41)$ & & & $53 \pm 13(\mathrm{n}=5)$ & \\
\hline
\end{tabular}

BF: biochemical failure; BFFS: biochemical failure-free survival; N: number of patients; n: number of remaining patients; PSA: prostate specific antigen; VEGF: vascular endothelial growth factor 
tients were grouped according to VEGF expression ( $\mathrm{p}=0.06$ ) (Table 2, Figure 1 a-e).

\section{DISCUSSION}

Radiation therapy (with or without hormonal therapy) is the primary treatment option for patients with clinically localized prostate cancer. Well-documented prognostic factors such as Tstage, Gleason score and PSA indicate the natural history of the disease and determine the recurrence risk $(10,11)$. However, it might be challenging to identify patients who are at increased risk for recurrence. Therefore, cellular and molecular biological markers that might better predict possible radiation therapy resistance and outcome are needed to make treatment decisions.

Folkman (12) showed that angiogenesis is a necessary component of solid tumor growth. VEGF is a key regulator of angiogenesis and is involved in tumor angiogenesis by increasing vascular permeability, endothelial cell growth, proliferation, migration and differentiation (13). VEGF overexpression takes place through the adaptation of the tumor microenvironment to hypoxia (14). Tumor hypoxia might be an explanation for treatment failure following radiation therapy. Hypoxia has been associated with poor prognosis in a variety of cancers including the stomach, the esophagus, the breast, the colorectum, the head and neck and the cervix $(15-20,3,4)$.

Some studies have reported a relationship between VEGF expression and poorer tumor control together with diminished survival following radiation therapy in different cancers such as the rectum, the breast and the cervix. Peng et al. (21) reported that VEGF expression may predict distant metastases and disease-free survival in stage III rectal cancer following preoperative radiation therapy and also suggested that inhibition of VEGF in combination with radiation therapy may improve outcome. Linderholm et al. (18) showed that high VEGF expression can point to a resistant phenotype for node-negative breast cancer patients treated with only locoregional radiation therapy, or indicate early metastases which requires treatment. Another study evaluating the relationship between VEGF expression and radiation therapy outcome in advanced cervical cancer reported that expression of VEGF, as assessed by IHC analysis, is a highly significant prognostic factor for survival and metastasis-free survival but not for local control (22).

For clinically localized prostate cancer, the role of tumor hypoxia and angiogenesis has recently come under the spotlight. The presence of hypoxic regions in prostate cancer has been documented in the literature, both through the use of physical measurements (such as the $\mathrm{pO}_{2}$ probes) and the identification of specific biomarkers. In their study on patients with localized prostate cancer, Movsas et al. (2) reported that tumor hypoxia was associated with poor prognosis, since low $\mathrm{pO}_{2}$ levels (measured by an Eppendorf microelectrode) in the prostate were associated with higher BF assessed by PSA. Furthermore, Cvetkovic et al. (9) demonstrated a significant correlation between preoperative prostate hypoxia level (assessed by an Eppendorf oxygen microelectrode) and the percentage of cells staining positive for VEGF. One of the earliest VEGF expression studies showed that the majority of prostatic carcinoma specimens exhibited cytoplasmic staining for VEGF, with VEGF expression increasing with dedifferentiation of the tumor (23). Peyromaure et al. (24) studied VEGFA expression in prostate cancer patients undergoing radical prostatectomy. They found higher expression of VEGF in men who developed bone metastases as compared to those who remained free of recurrence following surgery. As a result, they suggested that VEGF expression could be a factor associated with cancer progression following radical prostatectomy.

In the present study, higher VEGF expression was observed in $27 \%$ of patients with a low clinical T stage as compared to $58 \%$ of patients with a high clinical T stage. VEGF was overexpressed in $33 \%$ of patients with a low initial PSA level as compared to $50 \%$ of patients with a high initial PSA level. On the contrary, higher VEGF expression was observed in $23 \%$ of patients with a low Gleason score as compared to $73 \%$ of patients with a high Gleason score. Furthermore, BF was observed in $8 \%$ of patients with a low VEGF expression as compared to of $41 \%$ of patients with a high VEGF expression. The BFFS rate at 5 years was $91 \%$ for patients with a low VEGF expression versus $53 \%$ for patients with a high VEGF expression. There have only been a few studies that differentiated patients with radiation therapy sensitive prostate cancer from those with a poor outcome. In agreement with the results of our study, Green et al. (25) reported that higher tumor VEGF expression on pretreatment biopsies was correlated with an adverse outcome following radiation therapy. They found that VEGF was the only significant prognostic factor in terms of disease-specific survival $(p=0.035)$. They also reported a statistically significant association between high VEGF expression and increased Gleason score $(\mathrm{p}=0.02)$, but failed to observe any correlation between VEGF expression and $\mathrm{BF}$, in contrast with the results of our study. Vergis et al. (7) evaluated intrinsic markers of hypoxia and angiogenesis (HIF-1 $\alpha$, osteopontin and VEGF) in relation to the outcome of localized prostate cancer patients who were treated with curative intent, either using radical radiation therapy or radical prostatectomy. They reported that increased expression of VEGF was a significant predictor of worse freedom from BF for patients treated with radical radiation therapy as well as those treated with radical prostatectomy, in agreement with the results of our study.

In an attempt to define patients with clinically localized prostate cancer who are sensitive to standard treatment modalities such as surgery, radiation therapy and hormonal therapy, it is clear that cellular and/or molecular biological markers are 
a

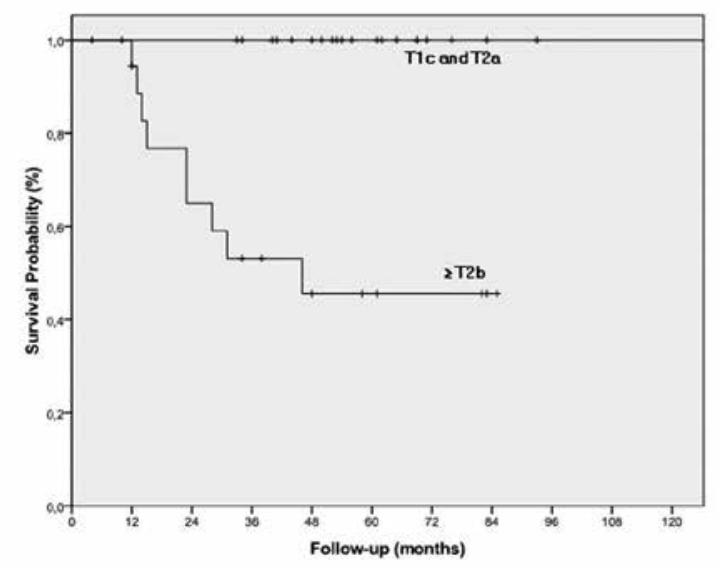

c

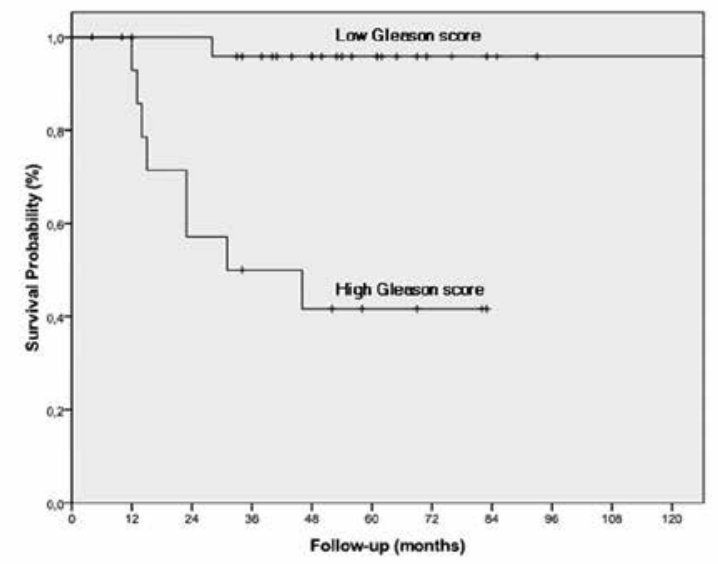

b

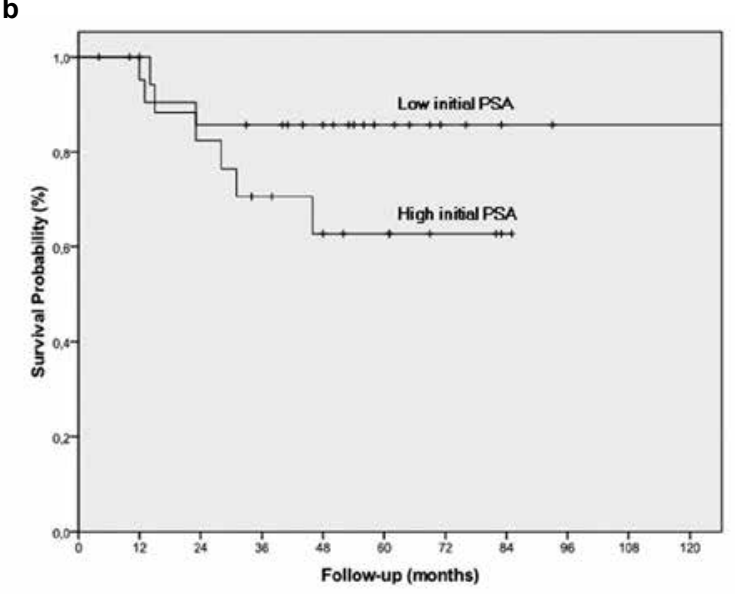

d

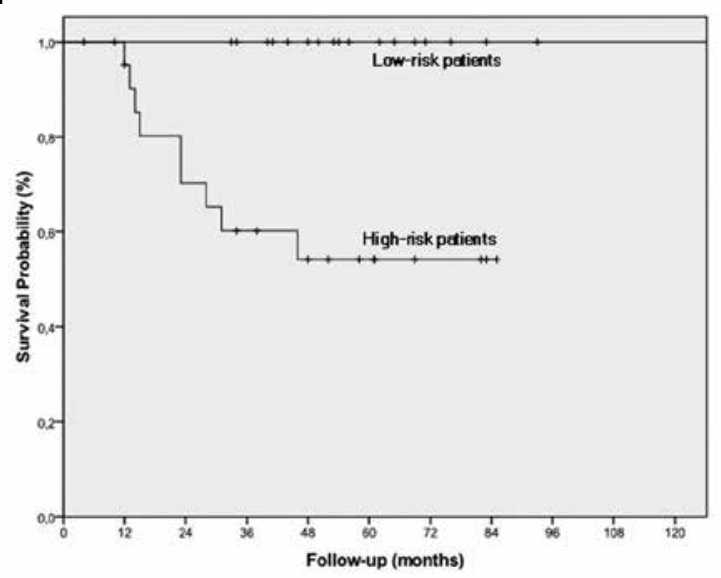

e

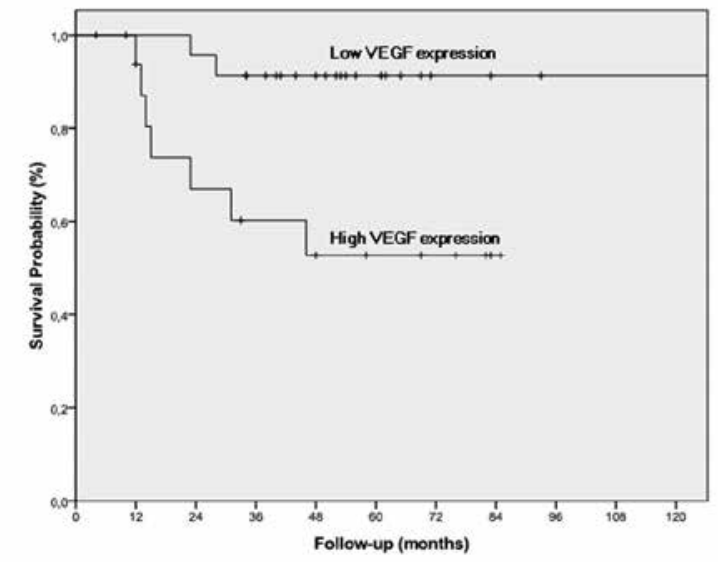

FIG. 1. a-e. Biochemical failure-free survival compared according to clinical T stage (a). Biochemical failure-free survival compared according to initial PSA level (b). Biochemical failure-free survival compared according to Gleason score (c). Biochemical failure-free survival compared according to risk groups (d). Biochemical failure-free survival compared according to VEGF expression (e) 
required. The relationship between VEGF and prostate cancer has been extensively studied. However, only a small number of studies evaluated the effects of VEGF expression on outcome, regardless of the treatment modality used. Furthermore, these studies were underpowered in terms of both the number of patients involved and the extent of follow-up. Vergis et al. (7) speculated that the associations between clinical outcome and staining for VEGF (as well as other markers of hypoxia such as HIF-1 $\alpha$ and osteopontin) are not sufficient to conclude that tumor hypoxia and angiogenesis adversely affect treatment efficacy and that these markers constitute therapeutic targets. Furthermore, they suggested that "VEGF might only serve as one of the markers pointing to an aggressive tumor type". It is for the aggressive counterparts of prostate cancer that antiVEGF treatments could prove beneficial. Recent preclinical studies have shown that anti-VEGF agents can "normalize" tumor associated blood vessels, which is a mechanism of radiosensitization $(26,27)$. Based on the results of these preclinical studies, Vuky et al. (28) designed a phase II study examining the effect of an anti-VEGF agent concurrently with radiation therapy for high risk prostate cancer. They reported that the anti-VEGF agent did not appear to exacerbate the acute effects of radiation therapy; however, the impact on outcome remained unclear. Therefore, as a conclusion, further investigations that aimed to associate VEGF as well as other markers of angiogenesis and hypoxia with treatment outcome are required for patients with clinically localized prostate cancer.

Ethics Committee Approval: At the time of the study, an Ethics Committee approval was not a requirement for retrospective studies at the Institution where the study was undertaken. Therefore, no application was made for an Ethics Committee approval for this retrospective study.

Informed Consent: Informed consent was obtained from patients who participated in this study.

\section{Peer-review: Externally peer-reviewed.}

Author contributions: Concept - E.Y.E.; Design - E.Y.E., H.B.; Supervision -H.B., M.A.; Resource - M.A., M.T.; Materials - H.B., M.T., M.A.; Data Collection\&/or Processing - E.Y.E.; Analysis\&/or Interpretation - E.Y.E., H.B., M.A.; Literature Search - E.Y.E.; Writing - E.Y.E., H.B.; Critical Reviews - E.Y.E., H.B., M.A.

Conflict of Interest: No conflict of interest was declared by the authors.

Financial Disclosure: The authors declared that this study has received no financial support.

\section{REFERENCES}

1. Bolla M, Van Tienhoven G, Warde P, Dubois JB, Mirimanoff RO, Storme $\mathrm{G}$, et al. External irradiation with or without long-term androgen suppression for prostate cancer with high metastatic risk: 10-year results of an EORTC randomised study. Lancet Oncol 2010;11:1066-73. [CrossRef]

2. Movsas B, Chapman JD, Hanlon AL, Horwitz EM, Greenberg RE, Stobbe $\mathrm{C}$, et al. Hypoxic prostate/muscle $\mathrm{pO} 2$ ratio predicts for biochemical failure in patients with prostate cancer: preliminary findings. Urology 2002;60:634-9. [CrossRef]
3. Nordsmark M, Overgaard M, Overgaard J. Pretreatment oxygenation predicts radiation response in advanced squamous cell carcinoma of the head and neck. Radiother Oncol 1996;41:31-9. [CrossRef]

4. Fyles AW, Milosevic M, Wong R, Kavanagh MC, Pintilie M, Sun A, et al. Oxygenation predicts radiation response and survival in patients with cervix cancer. Radiother Oncol 1998;48:149-56. [CrossRef]

5. Lee CG, Heijn M, di Tomaso E, Griffon-Etienne G, Ancukiewicz M, Koike $\mathrm{C}$, et al. Anti-Vascular endothelial growth factor treatment augments tumor radiation response under normoxic or hypoxic conditions. Cancer Res 2000;60:5565-70.

6. Geng L, Donnelly E, McMahon G, Lin PC, Sierra-Rivera E, Oshinka H, et al. Inhibition of vascular endothelial growth factor receptor signaling leads to reversal of tumor resistance to radiotherapy. Cancer Res 2001;61:2413-9.

7. Vergis R, Corbishley CM, Norman AR, Bartlett J, Jhavar S, Borre M, et al. Intrinsic markers of tumour hypoxia and angiogenesis in localised prostate cancer and outcome of radical treatment: a retrospective analysis of two randomised radiotherapy trials and one surgical cohort study. Lancet Oncol 2008;9:342-51. [CrossRef]

8. D'Amico AV, Whittington R, Malkowicz SB, Schultz D, Blank K, Broderick GA, et al. Biochemical outcome after radical prostatectomy, external beam radiation therapy, or interstitial radiation therapy for clinically localized prostate cancer. JAMA 1998;280:969-74. [CrossRef]

9. Cvetkovic D, Movsas B, Dicker AP, Hanlon AL, Greenberg RE, Chapman JD, et al. Increased hypoxia correlates with increased expression of the angiogenesis marker vascular endothelial growth factor in human prostate cancer. Urology 2001;57:821-5. [CrossRef]

10. Cuzick J, Fisher G, Kattan MW, Berney D, Oliver T, Foster CS, et al. Transatlantic Prostate Group. Long-term outcome among men with conservatively treated localised prostate cancer. $\mathrm{Br} J$ Cancer 2006;95:1186-94. [CrossRef]

11. Stephenson AJ, Scardino PT, Eastham JA, Bianco FJ Jr, Dotan ZA, Fearn $\mathrm{PA}$, et al. Preoperative nomogram predicting the 10 -year probability of prostate cancer recurrence after radical prostatectomy. J Natl Cancer Inst 2006;98:715-7. [CrossRef]

12. Folkman J. Anti-angiogenesis: new concept for therapy of solid tumors. Ann Surg 1972;175:409-16. [CrossRef]

13. Hicklin DJ, Ellis LM. Role of the vascular endothelial growth factor pathway in tumor growth and angiogenesis. J Clin Oncol 2005;23:1011-27. [CrossRef]

14. Pugh CW, Ratcliffe PJ. Regulation of angiogenesis by hypoxia: role of the HIF system. Nat Med 2003;9:677-84. [CrossRef]

15. Maeda K, Chung YS, Ogawa Y, Takatsuka S, Kang SM, Ogawa M, et al. Prognostic value of vascular endothelial growth factor expression in gastric carcinoma. Cancer 1996;77:858-63. [CrossRef]

16. Inoue K, Ozeki Y, Suganuma T, Sugiura Y, Tanaka S. Vascular endothelial growth factor expression in primary esophageal squamous cell carcinoma. Association with angiogenesis and tumor progression. Cancer 1997;79:206-13. [CrossRef]

17. Linderholm B, Tavelin B, Grankvist K, Henriksson R Vascular endothelial growth factor is of high prognostic value in node-negative breast carcinoma. J Clin Oncol 1998;16:3121-8.

18. Linderholm B, Tavelin B, Grankvist K, Henriksson R. Does vascular endothelial growth factor (VEGF) predict local relapse and survival in radiotherapy-treated node-negative breast cancer? $\mathrm{Br} \mathrm{J}$ Cancer 1999;81:727-32. [CrossRef]

19. Linderholm B, Grankvist K, Wilking N, Johansson M, Tavelin B, Henriksson R. Correlation of vascular endothelial growth factor content with recurrences, survival, and first relapse site in primary node-positive breast carcinoma after adjuvant treatment. J Clin Oncol 2000;18:1423-31.

20. Ishigami SI, Arii S, Furutani M, Niwano M, Harada T, Mizumoto M, et al. Predictive value of vascular endothelial growth factor (VEGF) in metastasis and prognosis of human colorectal cancer. $\mathrm{Br} J$ Cancer 1998;78:1379-84. [CrossRef] 
21. Peng Y, Wang L, Du C, Gu J. Expression of vascular endothelial growth factor can predict distant metastasis and disease-free survival for clinical stage III rectal cancer following 30-Gy/10-f preoperative radiotherapy. Int J Colorectal Dis 2012;27:1555-60. [CrossRef]

22. Loncaster JA, Cooper RA, Logue JP, Davidson SE, Hunter RD, West CM. Vascular endothelial growth factor (VEGF) expression is a prognostic factor for radiotherapy outcome in advanced carcinoma of the cervix. Br J Cancer 2000;83:620-5. [CrossRef]

23. Harper ME, Glynne-Jones E, Goddard L, Thurston VJ, Griffiths K. Vascular endothelial growth factor (VEGF) expression in prostatic tumours and its relationship to neuroendocrine cells. $\mathrm{Br} J$ Cancer 1996;74:910-6. [CrossRef]

24. Peyromaure M, Camparo P, Badoual C, Descazeaud A, Dinh-Xuan AT. The expression of vascular endothelial growth factor is associated with the risk of cancer progression after radical prostatectomy. BJU Int 2007;99:1150-3. [CrossRef]
25. Green MM, Hiley CT, Shanks JH, Bottomley IC, West CM, Cowan RA, et al. Expression of vascular endothelial growth factor (VEGF) in locally invasive prostate cancer is prognostic for radiotherapy outcome. Int $J$ Radiat Oncol Biol Phys 2007;67:84-90. [CrossRef]

26. Tong RT, Boucher Y, Kozin SV, Winkler F, Hicklin DJ, Jain RK. Vascular normalization by vascular endothelial growth factor receptor 2 blockade induces a pressure gradient across the vasculature and improves drug penetration in tumors. Cancer Res 2004;64:3731-6. [CrossRef]

27. Winkler F, Kozin SV, Tong RT, Chae SS, Booth MF, Garkavtsev I, et al. Kinetics of vascular normalization by VEGFR2 blockade governs brain tumor response to radiation: role of oxygenation, angiopoietin-1, and matrix metalloproteinases. Cancer Cell 2004;6:553-63. [CrossRef]

28. Vuky J, Pham HT, Warren S, Douglass E, Badiozamani K, Madsen B, et al. Phase II study of long-term androgen suppression with bevacizumab and intensity-modulated radiation therapy (IMRT) in high-risk prostate cancer. Int J Radiat Oncol Biol Phys 2012;82:e609-15. [CrossRef] 